\title{
A Numerical Swallowing-Capacity Analysis of a Vacant, Cylindrical, Bi-Directional Tidal Turbine Duct in Aligned \& Yawed Flow Conditions
}

\author{
Mitchell G. Borg ${ }^{1}\left(\mathbb{D}\right.$, Qing Xiao ${ }^{1, *} \oplus$, Steven Allsop ${ }^{2}$, Atilla Incecik ${ }^{1}$ and Christophe Peyrard ${ }^{3}$ \\ 1 Department of Naval Architecture, Ocean, and Marine Engineering, University of Strathclyde, \\ Glasgow G4 0LZ, UK; mitchell.borg@strath.ac.uk (M.G.B.); atilla.incecik@strath.ac.uk (A.I.) \\ 2 Industrial Doctoral Centre for Offshore Renewable Energy (IDCORE), University of Edinburgh, \\ Edinburgh EH8 9YL, UK; Steve.Allsop@simecatlantis.com \\ 3 Électricité de France Research and Development, EDF R\&D, Ile-de-France, 78400 Chatou, France; \\ christophe.peyrard@edf.fr \\ * Correspondence: qing.xiao@strath.ac.uk
}

check for

updates

Citation: Borg, M.G.; Xiao, Q.; Allsop, S.; Incecik, A.; Peyrard, C. A Numerical Swallowing-Capacity Analysis of a Vacant, Cylindrical, Bi-Directional Tidal Turbine Duct in Aligned \& Yawed Flow Conditions. J. Mar. Sci. Eng. 2021, 9, 182. https:// doi.org/10.3390/jmse9020182

Academic Editor:

Alessandro Antonini

Received: 31 December 2020

Accepted: 2 February 2021

Published: 10 February 2021

Publisher's Note: MDPI stays neutral with regard to jurisdictional claims in published maps and institutional affiliations.

Copyright: (c) 2021 by the authors. Licensee MDPI, Basel, Switzerland. This article is an open access article distributed under the terms and conditions of the Creative Commons Attribution (CC BY) license (https:// creativecommons.org/licenses/by/ $4.0 /)$.

\begin{abstract}
Introducing a duct along the perimeter of a rotor has been acknowledged to augment turbine performance. The outcome causation due to a bi-directional, cylindrical shroud, however, is uncertain. This study analyses the hydrodynamic swallowing capacity of a true-scale, vacant duct for tidal turbine applications in aligned and yawed inlet flow conditions by utilising threedimensional unsteady computational fluid dynamics. The performance is investigated within free-stream magnitudes of 1 to $7 \mathrm{~m} . \mathrm{s}^{-1}$, and a bearing angular range of $0^{\circ}$ to $45^{\circ}$ with the duct axis. In proportion to the free-stream magnitude, the normalised axial velocity through the duct increases as a result of a diminishment in pressure drag. Within yawed flow, the maximum capacity falls at a bearing of $23.2^{\circ}$, resulting in a performance increase of $4.13 \%$ above that at aligned flow conditions. The analysis concludes that the augmentation at yawed flow occurs due to the duct cross-sectional profile lift variation with angle-of-attack. Towards nominal yaw angle, the internal static pressure reduces, permitting a higher mass-flow rate. Beyond the nominal angle-of-attack, flow separation occurs within the duct, increasing pressure drag, thereby reducing the swallowing capacity.
\end{abstract}

Keywords: swallowing capacity; duct flow; ducted turbine

\section{Introduction}

The European Commission has put forward the 2030 Climate Target Plan. This strategy has proposed the reduction of greenhouse gas emissions to 55\% of the levels read in 1990 by 2030 [1]. It has sustained objectives stated within the Paris Agreement to limit the global temperature increase to below $2{ }^{\circ} \mathrm{C}$. In relation to the strategy, application of sustainable energy-generating systems is required.

Tidal stream turbine (TST) technology has been maturing over the past decade. Despite the potential, the industry has not prospered as rapidly as had been predicted. This outcome has been deemed to be due to engineering challenges within extreme operating conditions, in combination with political and environmental factors [2]. Despite the drawbacks observed within the tidal industry, European, North American, and Asian states have largely invested in the deployment of full-scale tidal turbine arrays. A wide range of the European investment has been installed within territorial waters of France and the United Kingdom [3].

Efforts to increase the efficacy of energy-generating turbines have been ongoing. From the undergone research, bi-directional ducts have been installed along the circumference of a rotor to increase the mass-flow, establishing a ducted turbine system [4]. An effective duct design in relation to the installed rotor is required to permit the highest swallowing capacity 
through the duct throat. By definition, swallowing capacity is described as the normalised axial velocity through the duct throat in relation to the external free-stream velocity.

Few research ventures have investigated the fluid dynamics of vacant, open-ended diffusers/ducts for rotor implementation within aligned and non-aligned flow conditions. Kogan and Seginer [5] described two driving factors that enhance the mass-flow rate. Primarily, a low-pressure region is produced downstream of the structure due to flow deviation from the diffuser outlet. The outlet region is therefore segregated from the energised free-stream, which draws in a larger amount of fluid. In addition, flow acceleration is induced by the areal contraction along the shroud throat within a streamtube, in accordance to Bernoulli's principle, as illustrated in Figure 1.

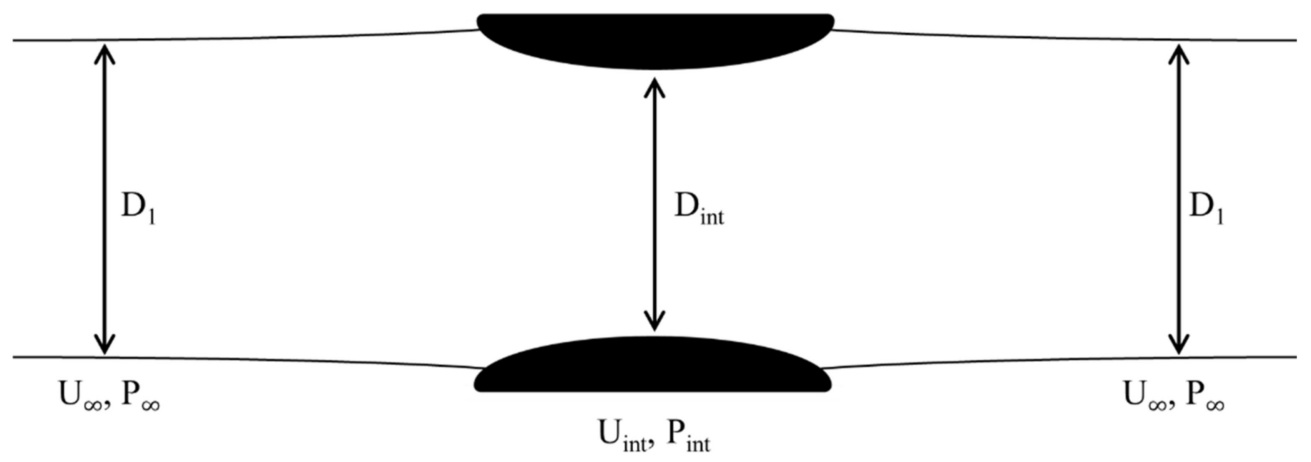

Figure 1. Bi-directional vacant duct streamtube representation.

Attributable to the potential increase in power extraction as a result of mass-flow increase through a rotor, several commercial endeavours had attempted to adopt ducted turbine technology to achieve economic prospects. Amongst the ventures, DCNS/OpenHydro Ltd. had designed an open-centre ducted design approach [6,7]. In open-water trials, a 2 MW turbine was successfully installed in the Bay of Fundy, Canada, portrayed in Figure 2 , together with a pair of $500 \mathrm{~kW}$ rated capacity turbines in Paimpol-Bréhat, Northern France, in collaboration with EDF France.

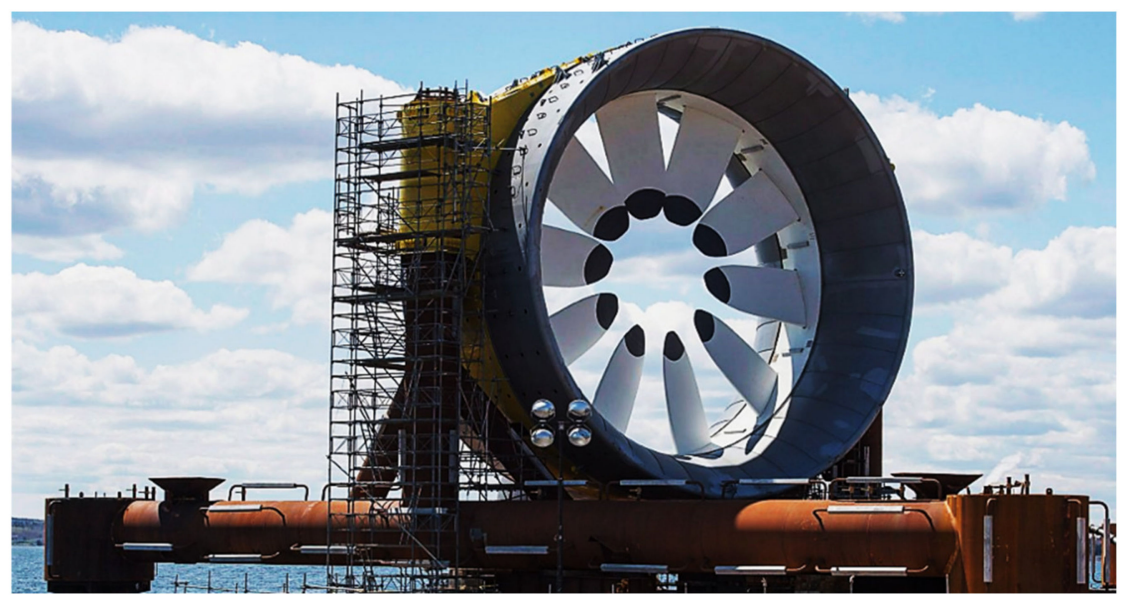

Figure 2. The $2 \mathrm{MW}$-rated OpenHydro ducted turbine. Adapted from [8], The Canadian Press/Andrew Vaughan, 2016.

Through the small number of published works, mass-flow augmentation within an open-ended duct for turbine implementation has been put forward. Ohya et al. [9] evaluated three distinct duct structures: nozzle, cylindrical, and diffuser form types. The cylindrical duct sustained an axial velocity relatively equivalent to the free-stream throughout its length. The diffuser-type accelerated the flow by a magnitude of 1.8 as a result of 
the negative static pressure induced, a -1.9 factor of the free-stream dynamic pressure. The nozzle-type attained a diminished mass-flow. Masukume et al. [10,11] varied the length to throat diameter ratio and expansion angle of a diffuser to establish the optimum geometrical shape parameters for maximum mass-flow. On average, a 1.5 magnitude over the free-stream velocity was attained through the diffuser at all combinations of length ratios and diffuser expansion angles.

In tidal current applications, Setoguchi et al. [12] developed three geometrical variations for a two-way, symmetrical, bi-directional diffuser: a shell-type, for unmodified control comparison; a straight-type, describing a solid diffuser with a straight outer duct surface; and a bulge-type, describing a solid diffuser with an outer duct surface mirroring the inner duct surface. By comparing the increase in axial velocity through the duct throat, the highest swallowing capacity was attained by the straight-type bi-directional diffuser with a vertical rim at the outlet. The flow within the duct was accelerated by a magnitude of 1.3. Cresswell et al. [13] analysed a vacant diffuser within aligned and yawed flow conditions. A static pressure variation along the internal and external surfaces of the diffuser was acknowledged with an increase in yaw bearing.

Numerically investigating the swallowing capacity of a vacant flanged duct, Kardous et al. [14] implemented an axi-symmetric computational fluid dynamic analysis utilising periodic boundary conditions. Variations in flow velocity and static pressure were established within the structure by varying the height of a straight rim at the diffuser outlet in relation to the throat diameter. A height ratio of 0.1 was found to attain the highest increase in throat velocity, equivalent to a magnitude of 1.6 to 1.7 over the free-stream velocity. Kannan et al. [15] investigated the variation in flow velocity within flanged diffuser geometrical profiles. A two-dimensional straight-body diffuser cone with a $16^{\circ}$ aperture, coupled with a $0.5 \mathrm{~m}$ long $4^{\circ}$ centre-body cone, was utilised. An increase in axial velocity of $61.25 \%$ over the free-stream was acknowledged.

Implementing axi-symmetric numerical models, Mansour and Meskinkhoda [16] applied both the Spalart-Allmaras and the RNG $k-\varepsilon$ turbulence model to determine the static pressure and axial velocity variations through a simple diffuser incorporated with a straight, vertical rim. Similarly, Khamlaj and Rumpfkeil [17] utilised the SST $k-\omega$ turbulence model to establish the generation of two static vortices downstream of the flange. Kesby et al. [18] investigated a $10^{\circ}$ diffuser to identify the efficiency coefficients of the structure for blade-element analysis implementation.

Considering yawed flow analysis, El-Zahaby et al. [19] investigated the swallowing capacity of a flanged diffuser designed for micro-turbines by establishing an inlet velocity bearing variation. Utilising a two-dimensional axi-symmetric model, the analysis ranged from $+25^{\circ}$ to $-25^{\circ}$ with the duct axis. The optimum angle, a bearing of $15^{\circ}$, accelerated the flow at the diffuser entrance by $5 \%$. Tampier et al. [20] numerically investigated the axial induction factor, average velocities at the turbine plane, and diffuser drag coefficient along a three-dimensional shroud in accordance with a variation in free-stream velocity.

Despite the undertaken research, the performance of a true-scale, three-dimensional, bi-directional, cylindrical duct has not been acknowledged. Due to its industrial implementation, the analysis was therefore deemed to be of particular interest, distinctively when considering the variable conditional parameters of an external fluid domain at differing free-stream magnitudes and yaw bearings. Therefore, the aim of this study was to analyse the swallowing-capacity performance of a true-scale bi-directional duct for tidal turbine applications in aligned and yawed flow conditions by utilising three-dimensional unsteady computational fluid dynamics (CFD). By means of the analysis, the causation of the performance variation may then be identified. The numerical analysis elaborated in this present study is a continuation of Borg et al. [21], which had developed a real-scale CFD model to assess the hydrodynamic performance of a high-solidity open-centre rotor within a bi-directional duct for tidal turbine applications in aligned flow conditions. The duct geometry was provided by EDF R\&D to replicate the outcomes of a turbine similar to the design of the OpenHydro PS2 device, whilst coupling the seven-equation Reynolds 
Stress "Stress-Omega" Model ( $\tau-\omega)$ turbulence model to close the Navier-Stokes equation and analyse the anisotropic flow domain [22].

\section{Numerical Methodology}

\subsection{Physical Setup}

The dimensions of the cylindrical bi-directional duct describe an external duct diameter $\left(D_{\text {ext }}\right)$ of $15 \mathrm{~m}$, an internal duct diameter $\left(D_{\text {int }}\right)$ of $12 \mathrm{~m}$, with a flat-convex cross-sectional profile, and a duct length $\left(L_{d c t}\right)$ of $10 \mathrm{~m}$, as illustrated in Figure $3 \mathrm{a}, \mathrm{b}$. The flow parameters were considered from site analyses that had established a maximum acquired spring tide velocity of $4.0 \mathrm{~m} \cdot \mathrm{s}^{-1}$, and a surface velocity of $5.0 \mathrm{~m} \cdot \mathrm{s}^{-1}[23,24]$. In recognition of the literature, free-stream velocity $\left(U_{\infty}\right)$ magnitudes of $1.0,2.5,4.0,5.5$, and $7.0 \mathrm{~m} . \mathrm{s}^{-1}$ were analysed to establish a variation between low and extreme current conditions. Additionally, the tidal cycle at the Paimpol-Bréhat site had been numerically simulated $[25,26]$. An asymmetric velocity was acknowledged in both magnitude and direction, at ebb and flood, with an average-depth angular discrepancy of $20^{\circ}$. Therefore, yaw bearing $(\gamma)$ angles of $0^{\circ}, 7^{\circ}, 15^{\circ}, 23.2^{\circ}, 27^{\circ}, 30^{\circ}, 38^{\circ}$, and $45^{\circ}$, incoming from the turbine port direction at a magnitude of $4 \mathrm{~m} . \mathrm{s}^{-1}$, were investigated to establish the duct swallowing capacity under non-aligned flow conditions. The considered conditions are summarised in Tables 1 and 2. The simulations implemented an inlet turbulence intensity of $3 \%$ and an inlet turbulent length scale of $1 \mathrm{~m}$.

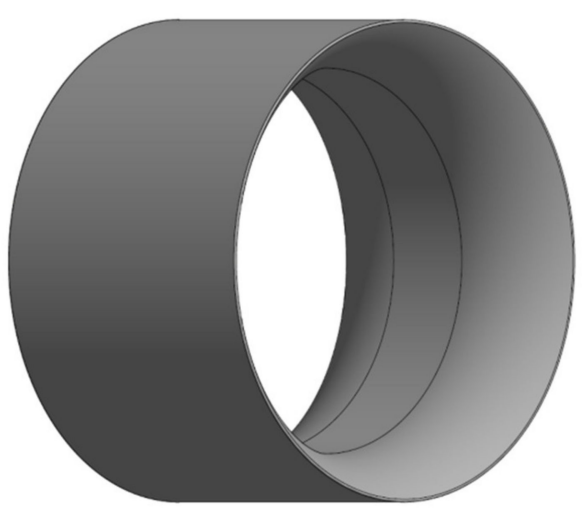

(a)
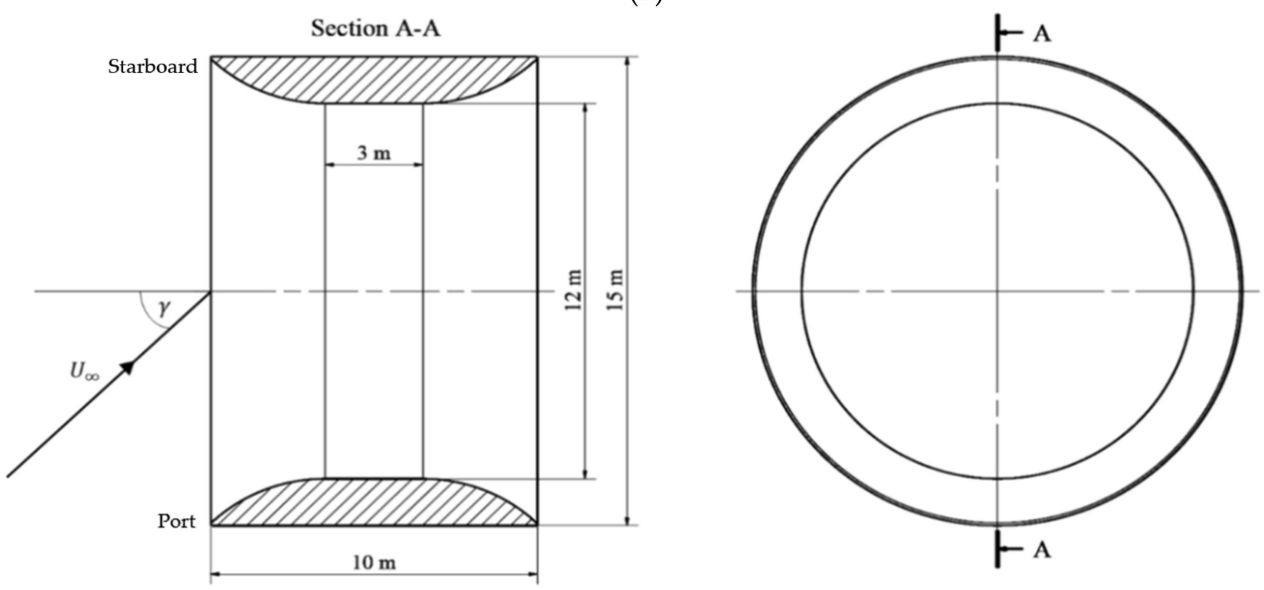

(b)

Figure 3. Geometric representation of the duct. (a) Rendered three-dimensional CAD representation; (b) First-angle sectioned projection. 
Table 1. Duct model descriptions.

\begin{tabular}{cc}
\hline Description & Value \\
\hline Duct external diameter $\left(D_{\text {ext }}\right)$ & $15 \mathrm{~m}$ \\
Duct internal radius $\left(D_{\text {int }}\right)$ & $12 \mathrm{~m}$ \\
Duct length $\left(L_{d c t}\right)$ & $10 \mathrm{~m}$ \\
Reynolds number $(R e)$ & {$[0.149-1.046] \times 10^{8}$} \\
\hline
\end{tabular}

Table 2. Domain model descriptions.

\begin{tabular}{ccc}
\hline Description & Aligned Flow & Yawed Flow \\
\hline Free-stream velocity $\left(U_{\infty}\right)$ & $1 \mathrm{~m} \cdot \mathrm{s}^{-1}, 2.5 \mathrm{~m} \cdot \mathrm{s}^{-1}, 4 \mathrm{~m} \cdot \mathrm{s}^{-1}, 5.5 \mathrm{~m} \cdot \mathrm{s}^{-1}, 7 \mathrm{~m} \cdot \mathrm{s}^{-1}$ & $4 \mathrm{~m} \cdot \mathrm{s}^{-1}$ \\
Yaw bearing $(\gamma)$ & $0^{\circ}$ & $0^{\circ}, 7^{\circ}, 15^{\circ}, 23.2^{\circ}, 27^{\circ}, 30^{\circ}, 38^{\circ}, 45^{\circ}$ \\
\hline
\end{tabular}

\subsection{Numerical Setup}

The duct model was designed to be a fully submerged system within a constant fluid flow. Far-stream effects from the free-surface and seabed were therefore abdicated. This setup permitted the swallowing-capacity analysis of the duct under consistent temporal conditions. The commercial solver ANSYS Fluent 19.2 was utilised in computing the continuity and Navier-Stokes equations. A Reynolds-averaged Navier-Stokes (RANS) turbulence model was implemented in mathematical closure to represent flow property fluctuation within the three-dimensional, unsteady, incompressible flow field.

Implementing a cuboidal domain layout, a cross-sectional quadratic-face edge-length of $7 D_{\text {ext }}$ was utilised. The cylindrical duct was positioned at the centre of the vertical plane. The dimensions of the computational domain attained a numerical areal blockage ratio of less than $2 \%$ to the external duct diameter to ascertain the absence of far-field effects [27]. A domain length of $9 D_{\text {ext }}$ was implemented, where the inlet and outlet planes were situated at a distance $3 D_{\text {ext }}$ upstream and $6 D_{\text {ext }}$ downstream of the duct, respectively, as illustrated in Figure 4a. The dimensions of the domain were therefore equivalent to 105 by 105 by $135 \mathrm{~m}$. The no-slip wall condition was implemented on the duct surface. Periodic conditions were allocated to the domain boundaries parallel to the duct axis. Velocity inlet and pressure outlet conditions were allocated to the perpendicular boundaries. The velocity yaw angle $(\gamma)$ was induced by varying the incident velocity components at the inlet boundary. Three circular planar numerical surfaces of diameter $D_{i n t}$ were introduced within the duct throat, at its upstream, middle, and downstream locations, as a rotor may be placed within this location. These surfaces were utilised for data acquisition purposes to attain mass-averaged values of normalised axial velocity and static pressure within the duct throat. The standard deviation of the mean-averaged results is presented in Appendix A.

The Reynolds-Stress Model (RSM) "Stress-Omega" $(\tau-\omega)$ turbulence model was utilised with the SIMPLE pressure-velocity coupling scheme, the Green-Gauss nodebased gradient, pressure staggering option (PRESTO) pressure, second order upwind momentum, second order upwind specific dissipation rate, and second order upwind Reynolds stresses spatial discretisation schemes, and the second order implicit transient formulation scheme. The Reynolds-Stress Model was utilised as the Reynolds stresses are solved in three-dimensional space due to the non-implementation of the Boussinesq approximation/assumption, prompting superiority in analysing anisotropic flows, such as flows over curved surfaces, flows in rotating fluids, and flows in ducts with secondary (rotational) motion [22]. In addition, the effects of streamline curvature, swirl, rotation, and rapid changes in strain rate are considered in a more effective manner than one-equation or two-equation models. The simulation time-step $\left(\Delta t_{s t e p}\right)$ was considered in relation to the duct length and free-stream velocity, where each transient iteration was attained by:

$$
\Delta t_{\text {step }}=0.01 \cdot \frac{L_{d c t}}{U_{\infty}}
$$




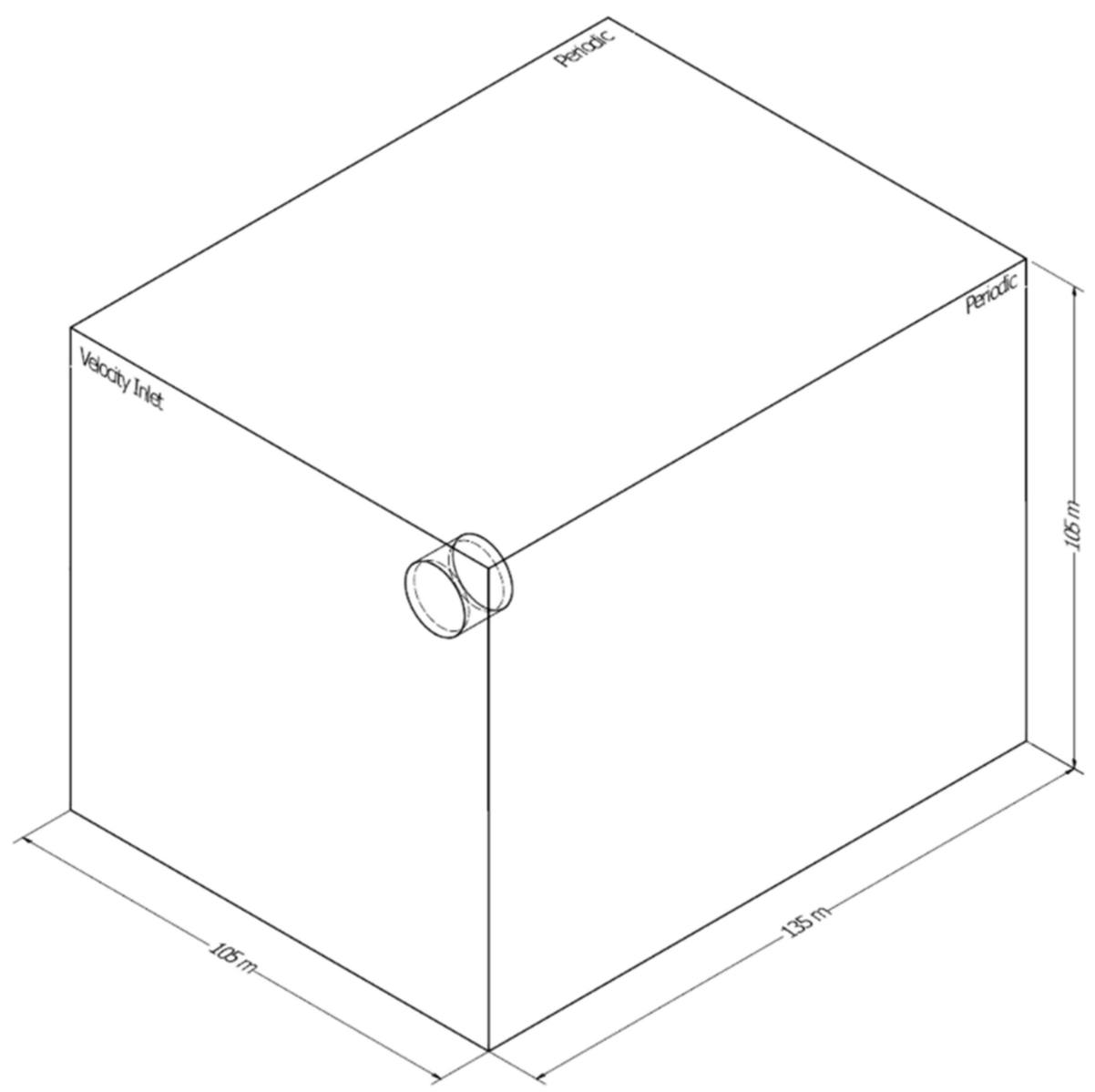

(a)

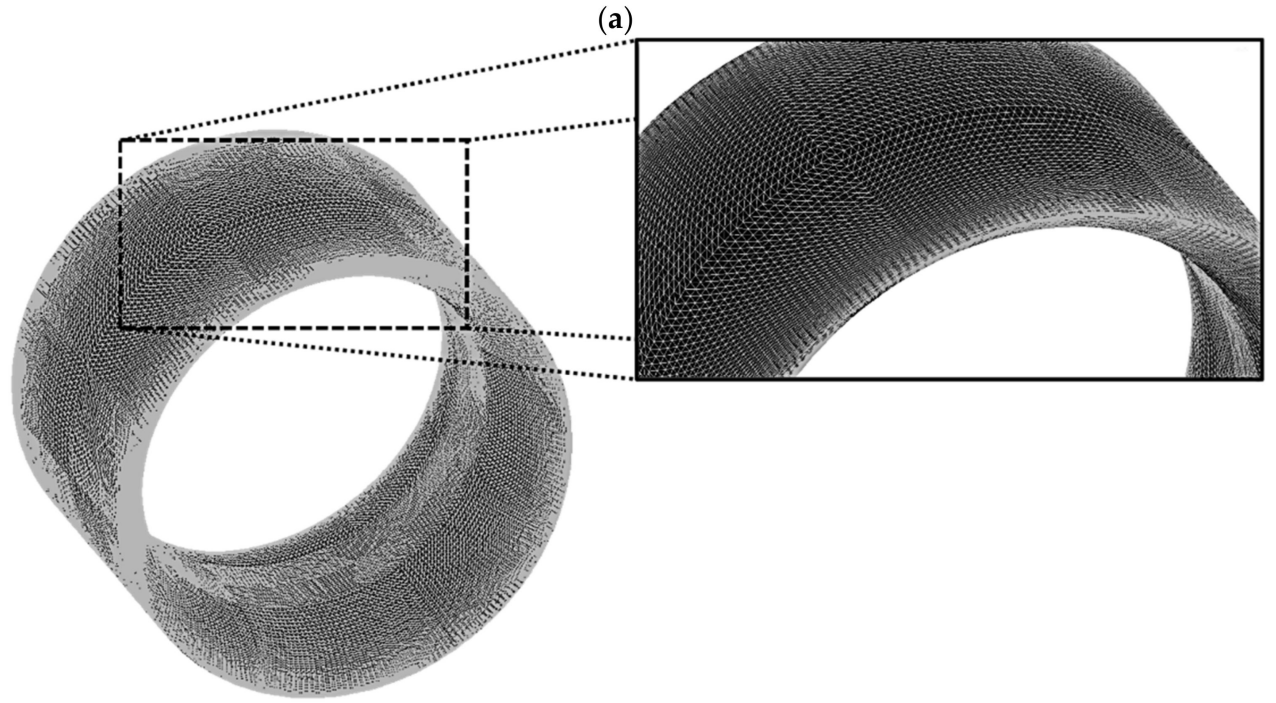

(b)

Figure 4. Representation of the domain (above, (a) CFD domain layout) and duct mesh (below, (b) Surface mesh along the duct.

The described numerical setup had been validated in previous works. The validation procedure consisted of a numerical-experimentation comparison of a small-scale tidal turbine. Details in relation to the setup of the numerical validation model may be attained in Ref. [21].

A tetrahedral mesh was utilised throughout the duct domain. A mesh independence procedure, described in Table 3, was carried out on the duct domain by considering the parameter with the highest degree of dynamics; the highest free-stream velocity. Mesh in- 
dependent parameters were established utilising ITTC recommended meshing procedures and guidelines [28]:

$$
\begin{gathered}
\varepsilon_{n}=S_{n}-S_{n-1} \\
\psi=\frac{\varepsilon_{n}}{\varepsilon_{n-1}}
\end{gathered}
$$

where $\psi$ is the convergence ratio, $\varepsilon$ is the difference between the considered variable $(S)$ at different mesh independence study iterations, and the subscript $n$ is the mesh independence study iteration.

Table 3. Mesh independence analysis for the duct domain.

\begin{tabular}{cccccc}
\hline$n$ & Cell Number & Cell Number Ratio & $S$ & $\varepsilon$ & $\psi$ \\
\hline 3 & $6,533,300$ & 1.247 & 1.493 & 0.0062 & 0.569 \\
2 & $5,240,241$ & 1.277 & 1.487 & 0.0109 & \\
1 & $4,103,210$ & & 1.476 & & \\
\hline
\end{tabular}

Subsequent to the procedure, the final surface mesh count upon the duct was marginally above 150,000 cell faces, illustrated in Figure $4 b$, with more than 6.5 million volumetric cells within the domain. The mesh was implemented with a prism layer at non-slip surfaces with an appropriate cell height to achieve a y-plus value of $60 \leqslant y^{+} \leqslant 400$. This range was considered due to the high Reynolds number $\left(>10^{7}\right)$ of the system; hence, modelling the viscous sublayer was abdicated to reduce computation time.

\section{Numerical Model Characterisation}

\subsection{Physical Modelling}

The induced normalised axial velocity through the duct throat $\left(U_{x}\right)$ was associated to the free-stream velocity $\left(U_{\infty}\right)$ to attain a quantitative measure of the swallowing capacity along the duct axis as a coefficient of axial velocity $\left(C_{U, x}\right)$ :

$$
C_{U, x}=\frac{U_{x}}{U_{\infty}}
$$

Similarly, the static pressure at the duct throat $\left(P_{s}\right)$ was associated to the dynamic pressure of the free-stream $\left(\frac{1}{2} \rho U_{\infty}^{2}\right)$ as a coefficient of static pressure $\left(C_{P, s}\right)$ :

$$
C_{P, s}=\frac{P_{s}}{\frac{1}{2} \rho U_{\infty}^{2}}
$$

where $\rho$ is the fluid density.

The Reynolds number $(R e)$ of the domain was defined as:

$$
R e=\frac{D_{e x t} U_{\infty} \rho}{\mu}
$$

where $D_{\text {ext }}$ is the duct external diameter and $\mu$ is the fluid dynamic viscosity.

Establishing the width of the streamtube at the far upstream position $\left(R_{1}\right)$ in relation to the duct external diameter, the conservation of mass equation, relating the mass flow-rate $(\dot{m})$ at the upstream position with that at the duct throat, was utilised:

$$
\begin{gathered}
\dot{m}_{\infty}=\dot{m}_{x} \\
\rho \pi R_{1}^{2} U_{\infty}=\rho \pi R_{\text {int }}^{2} U_{x} \\
\frac{R_{1}}{R_{\text {ext }}}=C_{R}=\frac{R_{\text {int }}}{R_{\text {ext }}} \cdot \sqrt{C_{U, x}}
\end{gathered}
$$


where $R_{\text {int }}$ is the duct internal radius, $R_{\text {ext }}$ is the duct external radius, and $C_{R}$ is the radius coefficient.

The drag and lift induced upon the duct were established within coefficients of drag and lift:

$$
\begin{gathered}
C_{D}=\frac{F_{D}}{\frac{1}{2} \rho A_{x} U_{\infty}^{2}}=\frac{F_{D}}{\frac{1}{2} \rho \pi R_{\text {ext }}^{2} U_{\infty}^{2}} \\
C_{L}=\frac{F_{L}}{\frac{1}{2} \rho A_{y} U_{\infty}^{2}}=\frac{F_{L}}{\frac{1}{2} \rho D_{\text {ext }} L_{d c t} U_{\infty}^{2}}
\end{gathered}
$$

where $C_{D}$ and $C_{L}$ are the drag and lift coefficient, $F_{D}$ and $F_{L}$ are the drag and lift forces, and $A_{x}$ and $A_{y}$ are the frontal areas in the axial and lateral directions, respectively.

\subsection{CFD Modelling}

\subsubsection{Conservation Modelling}

The conservation of mass and momentum were implemented within the CFD model in solving the flow domain:

$$
\begin{gathered}
\frac{\partial U_{i}}{\partial x_{i}}=0 \\
\rho \frac{\partial U_{i}}{\partial t}+\rho U_{j} \frac{\partial U_{i}}{\partial x_{j}}=-\frac{\partial P_{s}}{\partial x_{i}}+\frac{\partial}{\partial x_{j}}\left(\mu\left(\frac{\partial U_{i}}{\partial x_{j}}+\frac{\partial U_{i}}{\partial x_{j}}\right)-\rho u_{j}^{\prime} u_{i}^{\prime}\right)
\end{gathered}
$$

where $U_{i}$ is the Reynolds-averaged velocity, $x_{i}$ is the Cartesian coordinate, $t$ is the elapsed time, $\mu$ is the fluid dynamic viscosity, and $-\rho u_{j}^{\prime} u_{i}^{\prime}=\rho \tau_{i j}$ is the Reynolds stress tensor.

\subsubsection{Turbulence Modelling}

To close the momentum conservation equation, the $\tau-\omega$ turbulence model was implemented:

$$
\begin{array}{r}
\rho \frac{\partial \tau_{i j}}{\partial t}+\rho U_{k} \frac{\partial \tau_{i j}}{\partial x_{k}}=\frac{\partial}{\partial x_{k}}\left[\left(\mu+\frac{\mu_{\tau}}{\sigma_{k}}\right) \frac{\partial \tau_{i j}}{\partial x_{k}}\right]-\rho P_{i j}-\rho \Pi_{i j}+\frac{2}{3} \beta^{*} \rho \omega k \delta_{i j}-2 \rho \omega_{k}\left(\tau_{i j} \epsilon_{i k m}+\tau_{i m} \epsilon_{j k m}\right) \\
\rho \frac{\partial \omega}{\partial t}+\rho U_{j} \frac{\partial \omega}{\partial x_{j}}=\frac{\partial}{\partial x_{j}}\left[\left(\mu+\frac{\mu_{\tau}}{\sigma_{k}}\right) \frac{\partial \omega}{\partial x_{j}}\right]+\alpha_{1} \frac{\rho \omega}{k} \tau_{i j} \frac{\partial U_{i}}{\partial x_{j}}-\beta_{o} f_{\beta} \rho \omega^{2}
\end{array}
$$

where $\tau_{i j}$ is the specific Reynolds stress tensor, $k$ is the turbulence kinetic energy, $\omega$ is the specific dissipation rate, $\Pi_{i j}$ is the pressure-strain correlation tensor, $\mu_{T}$ is the eddy viscosity, $\omega_{k}$ is the rotation vector, $\epsilon_{i k m}$ is the Levi-Civita pseudotensor, $f_{\beta}$ is the mean rotation tensor factor, and $\sigma_{k}, \alpha_{1}, \beta^{*}$, and $\beta_{o}$ are closure coefficients.

\section{Modelling Validation}

Validation of the CFD model was attained in Ref. [21], where the numerical drag coefficient of a tidal turbine was compared to experimentation performed by Mycek et al. [29].

The drag coefficient curve was numerically established, illustrated in Figure 5. The CFD model attained a coefficient of determination of 0.946 with the experimentation data points within the entire curve. All CFD data points analysed, except for the low TSR value of 1.00 , fell within $2 \sigma_{C_{D}}$ (the 95th-percentile confidence range) of the experimentation points. 


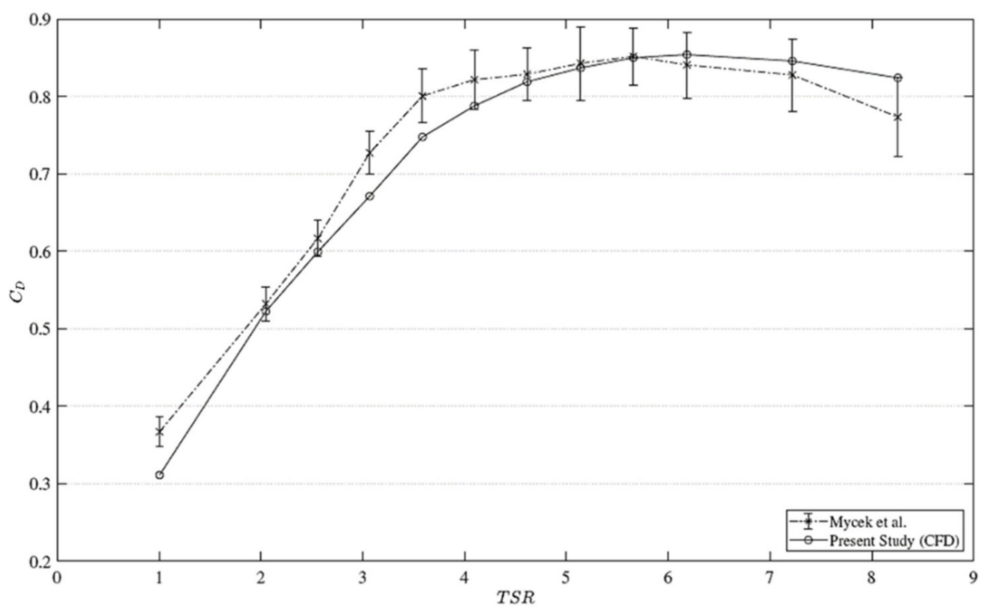

Figure 5. Drag coefficient $\left(C_{D}\right)$ in relation to tip-speed ratio (TSR) for validation of the CFD model by comparing a numerical tidal turbine model [21] to experimentation [29].

\section{Vacant Duct Performance in Aligned Flow Conditions}

\subsection{Drag Coefficient}

Analysing the vacant duct, the drag coefficient decreased from a value of 0.0641 to 0.0490 with a Reynolds number increase from $1.494 \times 10^{7}$ to $1.046 \times 10^{8}$, as illustrated in Figure 6. A laminar boundary layer transitions to a turbulent boundary layer earlier with an increase in Reynolds number, thereby enhancing flow attachment and diminishing drag. This phenomenon was acknowledged to be the driving factor behind the reduction in drag with an increase in free-stream velocity. The value of drag was minute due to the throat orifice constituting $64 \%$ of the frontal area. Distinguishing the total drag in its pressure and viscous components, both drag components reduced with an increase in Reynolds number, yet the pressure drag diminished more substantially in magnitude.

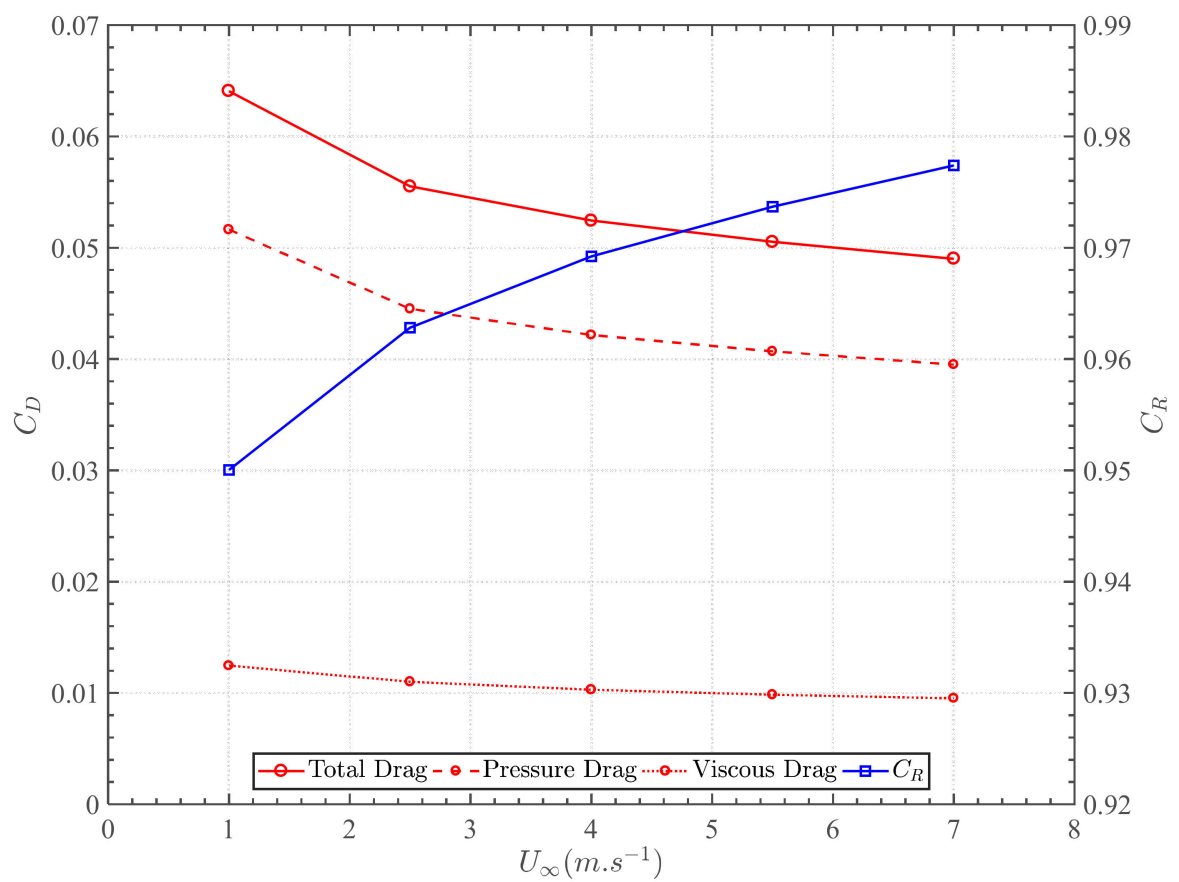

Figure 6. Evaluation of the duct drag coefficient $\left(C_{D}\right)$ and radius coefficient $\left(C_{R}\right)$ with free-stream velocity $\left(U_{\infty}\right)$ within aligned flow conditions. 


\subsection{Axial Velocity and Static Pressure}

Evaluating the variation in normalised axial velocity with free-stream velocity, the coefficient increased from a value of 1.410 to 1.493 in accordance with the Reynolds number increase, as illustrated in Figure 7. Similarly, the static pressure within the duct throat decreased along the Reynolds number range from a coefficient of -1.00 to -1.24 .

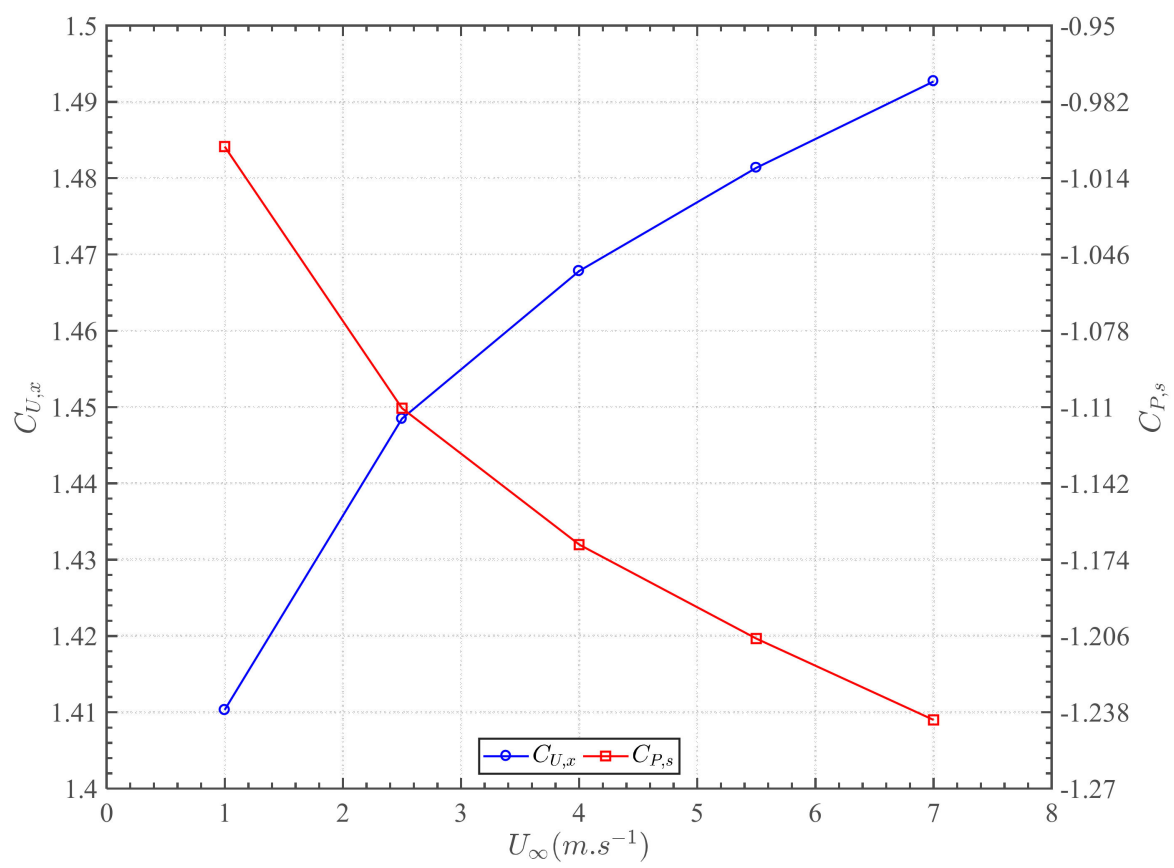

Figure 7. Evaluation of the throat axial velocity coefficient $\left(C_{U, x}\right)$ and static pressure coefficient $\left(C_{P, s}\right)$ with free-stream velocity $\left(U_{\infty}\right)$.

Primarily, the resultant normalised axial velocity occurred above the free-stream magnitude due to the contraction within the duct throat as a result of Bernoulli's principle. The supplementary increase, in relation to the Reynolds number, transpired due to the diminishing pressure drag, which permitted a higher normalised axial velocity within the duct throat, hence enhancing the swallowing capacity of the duct.

Furthermore, the one-dimensional mass-conservation formula was utilised to acquire the width of the fluid streamtube at a far upstream location in relation to the Reynolds number. The radius coefficient increased proportionally, as illustrated in Figure 6, establishing a larger mass-flow passing through the duct from an upstream position. In accordance with the increase due to the Bernoulli effect, however, it is unattainable for the upstream width $\left(D_{1}\right)$ to surpass the external duct width $\left(D_{\text {ext }}\right)$. Therefore, when considering an open-ended, cylindrical, bi-directional duct, the maximum axial velocity coefficient potentially attained is equivalent to the duct external-internal areal ratio $\left(D_{\text {ext }}^{2} / D_{\text {int }}^{2}\right)$.

\subsection{Duct Surface Static Pressure Coefficients}

The variation in static pressure along the inner and outer duct surfaces was analysed along a plane parallel to the free-stream vector, as illustrated in Figure 8. The stagnation point occurred at the leading edge of the internal duct surface. Wall static pressure diminished within the duct constriction towards the throat. Along the external surface, a dip in static pressure was acknowledged due to flow acceleration at the leading edge. A null gauge pressure was consistent along the external duct surface. 


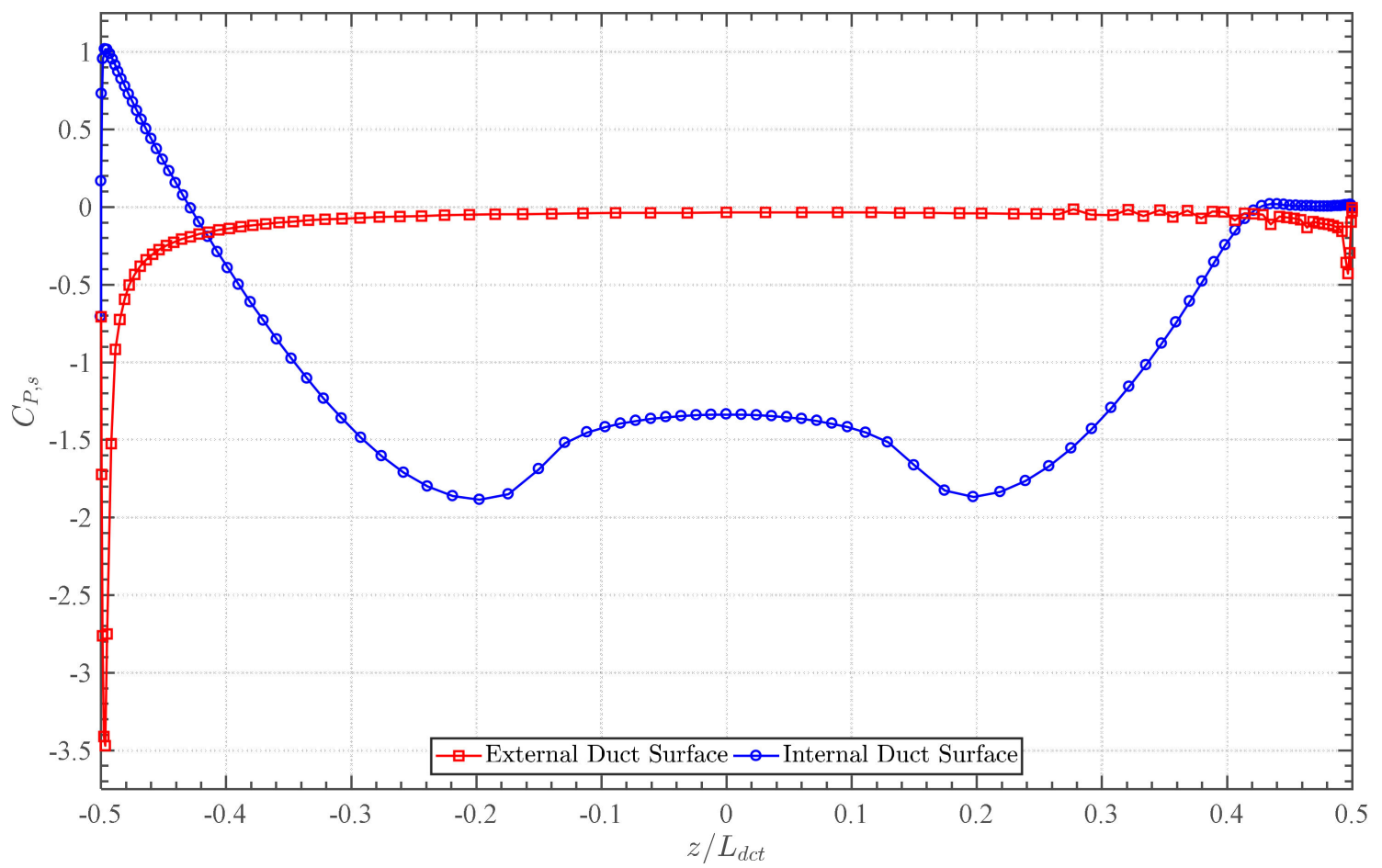

Figure 8. Pressure coefficient $\left(C_{P, s}\right)$ values along the external straight and internal curved duct surfaces $\left(U_{\infty}=4 \mathrm{~m} \cdot \mathrm{s}^{-1} ; \gamma=0^{\circ}\right)$.

\subsection{Wake Velocity Profiles}

The normalised axial velocity profiles of the duct wake were analysed from $0.5 D_{\text {ext }}$ to $6 D_{\text {ext }}$ downstream, as illustrated in Figure 9. Within the near-wake, at $0.5 D_{\text {ext }}$, the maximum axial velocity surpassed the free-stream along the duct throat region as a result of the internal flow acceleration. The velocity then diminished beyond the orifice region due to the presence of the duct ridges. The point of minima axial velocity was situated at the trailing edge of the ridge. Further downstream, the wake kinetic energy levelled along the plane, resulting in the velocity profile to be consistent with the free-stream at the far-wake location of $6 D_{\text {ext }}$.

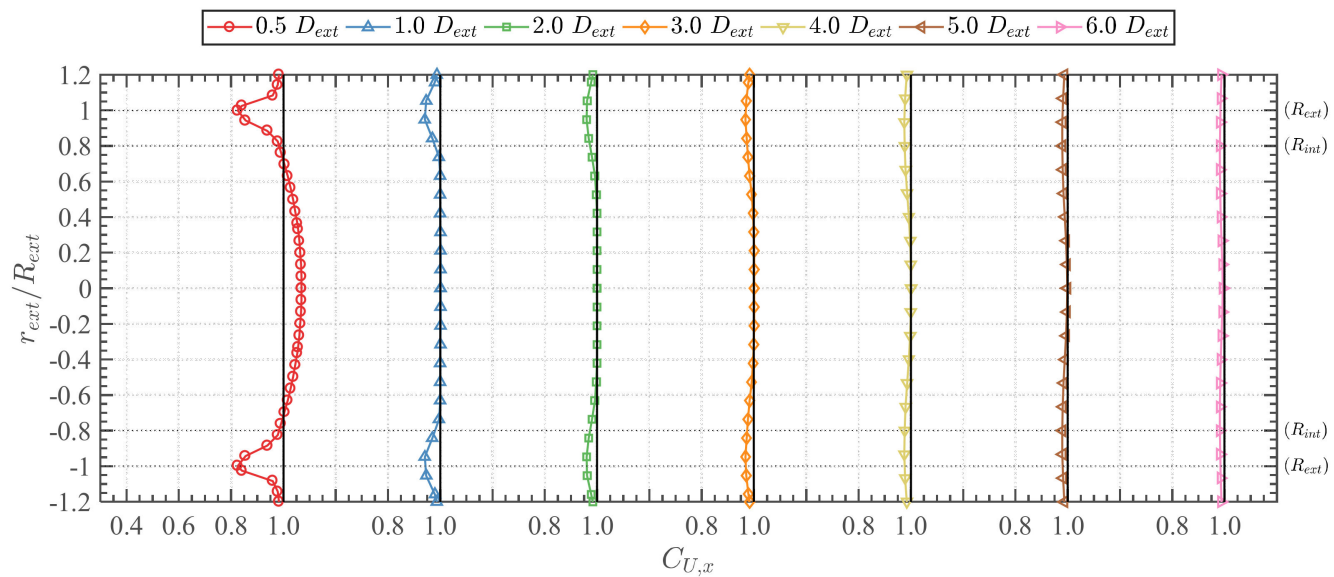

Figure 9. Axial velocity coefficient $\left(C_{U, x}\right)$ profiles within the duct wake at different downstream displacements $\left(U_{\infty}=4 \mathrm{~m} . \mathrm{s}^{-1}\right.$; $\left.\gamma=0^{\circ}\right)$. 


\section{Vacant Duct Performance in Yawed Flow Conditions \\ 6.1. Drag and Lift Coefficients}

Analysing the variation in drag in relation to the free-stream angular bearing, the coefficient decreased from a value of 0.0524 to -0.0690 at bearings from $0^{\circ}$ to $30^{\circ}$, as illustrated in Figure 10. The coefficient subsequently increased from -0.0690 to 0.303 at bearings from $30^{\circ}$ to $45^{\circ}$. The lift coefficient increased from a value of 0.0841 to 0.815 at bearings from $0^{\circ}$ to $30^{\circ}$, and decreased from 0.815 to 0.585 at bearings from $30^{\circ}$ to $45^{\circ}$. It should be stated that drag and lift were analysed parallel and perpendicular to the duct axis, rather than the free-stream vector, as upon installation the duct would be fixed to the seabed. The considered directions would be those of interest.

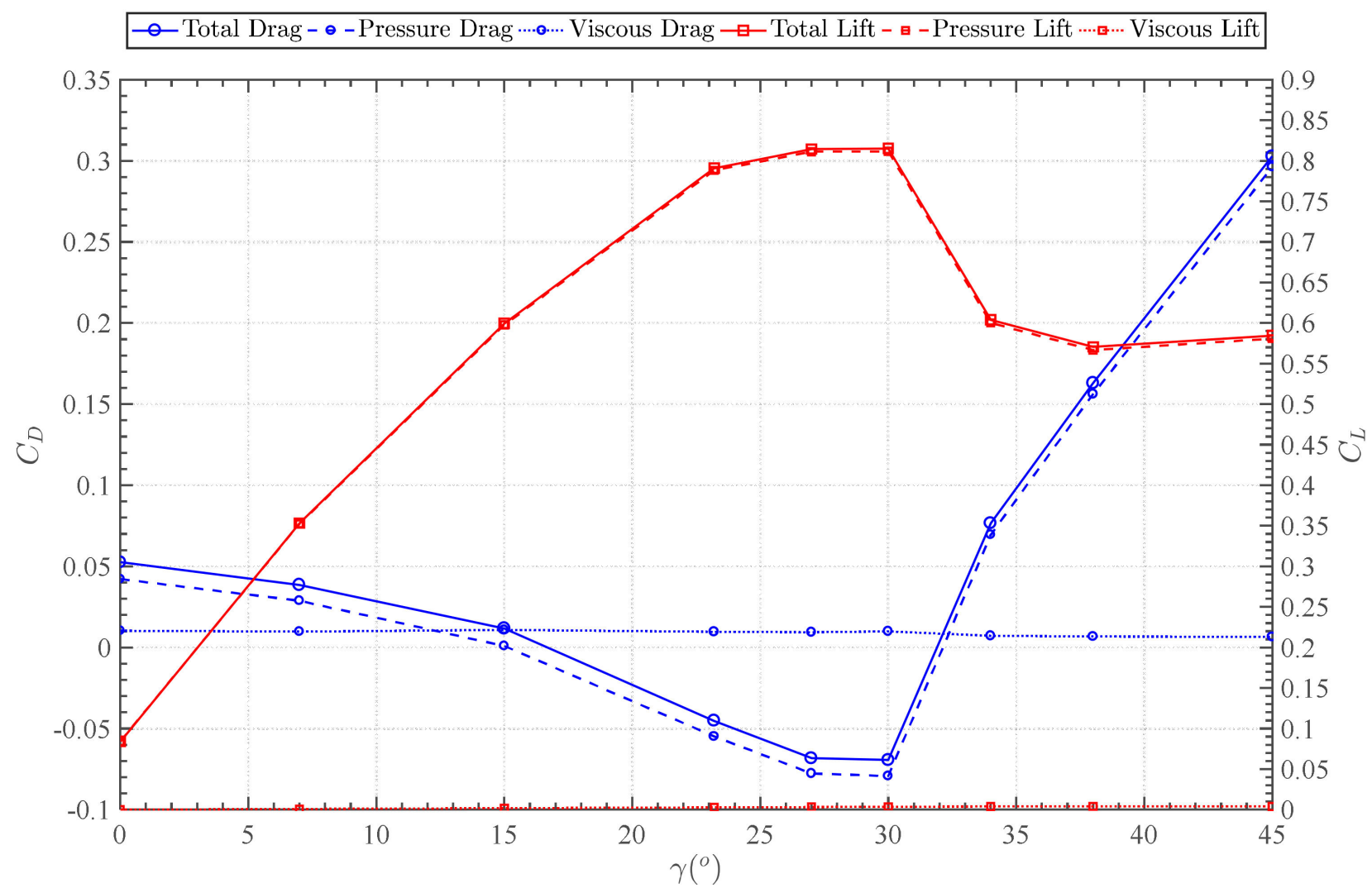

Figure 10. Evaluation of the duct drag coefficient $\left(C_{D}\right)$ and lift coefficient $\left(C_{L}\right)$ with yaw bearing $(\gamma)$ within a free-stream velocity $\left(U_{\infty}\right)$ of $4 \mathrm{~m} \cdot \mathrm{s}^{-1}$.

In recognition of the similarity to the drag and lift response of an aerofoil with angleof-attack, it was acknowledged that the duct static stall limit had therefore occurred at $30^{\circ}$, with the peak lift region initiating at a bearing of $23.2^{\circ}$. Distinguishing the total forces into pressure and viscous forces, the component of pressure was established to be the main variant factor within the dynamic system. The viscous component was consistently negligible. Therefore, in addition to the low pressure induced within the duct throat at aligned flow $\left(\gamma=0^{\circ}\right)$, an increase of the free-stream bearing augmented the low pressure further within the duct throat. This resulted in a total drag reduction with an increase in total lift.

Between a $23.2^{\circ}$ and $30^{\circ}$ bearing, a laminar separation bubble initiated along the internal wall region of the throat at port-side. Beyond a bearing of $30^{\circ}$, detachment of the laminar bubble occurred, increasing the pressure component of drag due to the flow separation, diminishing lift. 


\subsection{Axial Velocity and Static Pressure}

In accordance with the discrepancy in drag and lift, the variation in normalised axial velocity and static pressure within the duct throat was established, as illustrated in Figure 11. The velocity coefficient increased from a value of 1.47 to 1.53 at bearings from $0^{\circ}$ to $23.2^{\circ}$. The coefficient then decreased from 1.53 to 1.09 at bearings from $23.2^{\circ}$ to $45^{\circ}$. The static pressure coefficient decreased from -1.17 to -1.37 at bearings from $0^{\circ}$ to $23.2^{\circ}$, and increased from -1.37 to -0.49 at bearings from $23.2^{\circ}$ to $45^{\circ}$.

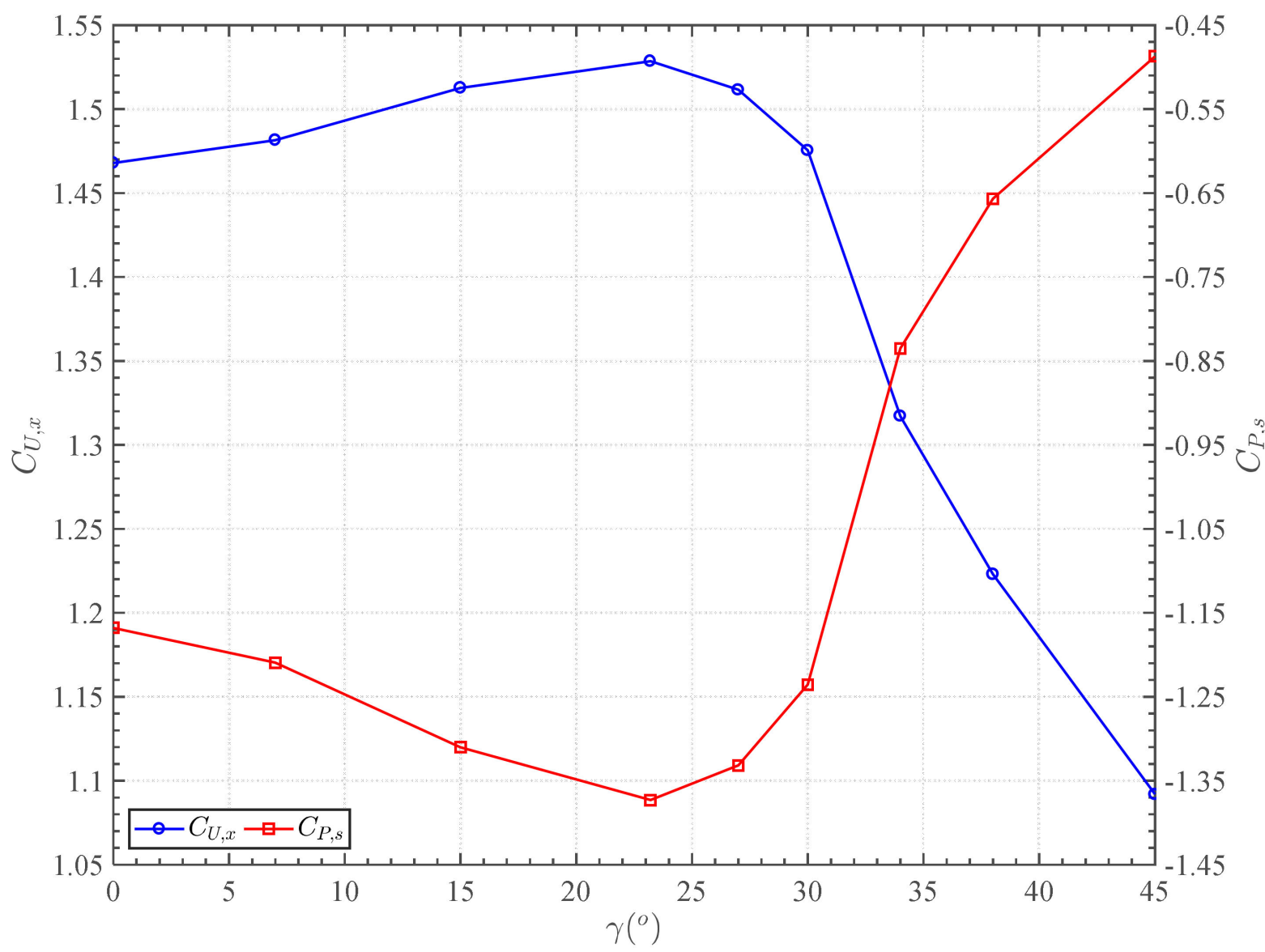

Figure 11. Evaluation of the throat axial velocity coefficient $\left(C_{U, x}\right)$ and static pressure coefficient $\left(C_{P, s}\right)$ with yaw bearing $(\gamma)$ within a free-stream velocity $\left(U_{\infty}\right)$ of $4 \mathrm{~m} . \mathrm{s}^{-1}$.

In contrast to the drag and lift curves, the maxima normalized axial velocity was attained at $23.2^{\circ}$, rather than at $30^{\circ}$. The generation of a laminar separation bubble, beyond the $23.2^{\circ}$ bearing, therefore resulted in the increase of static pressure within the crosssection of the throat orifice. Beyond $30^{\circ}$, the normalized axial velocity rate of change varied significantly due to the separation of the laminar bubble, increasing static pressure substantially. Contours depicting the flow variation through the cross-sectional duct domain at distinct bearings are illustrated in Figures 12 and 13. 


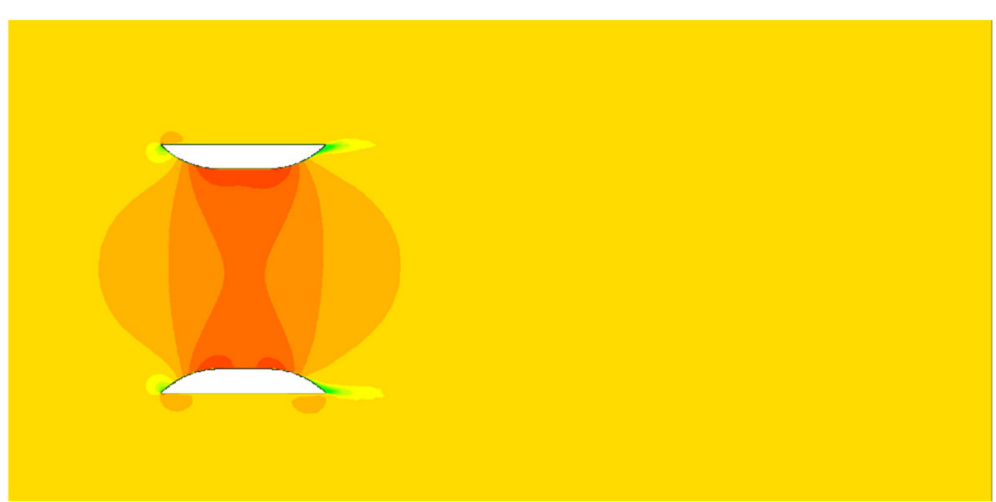

(a)
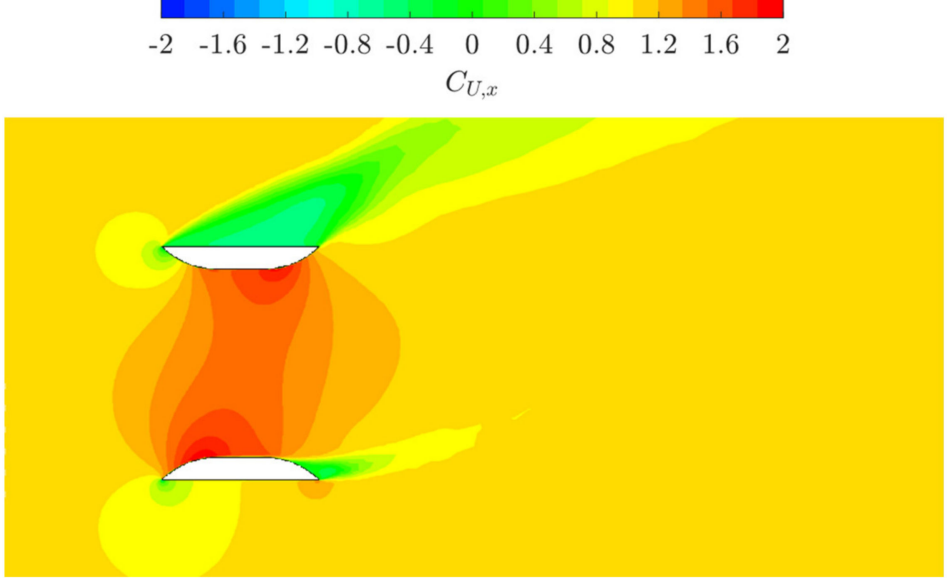

(b)
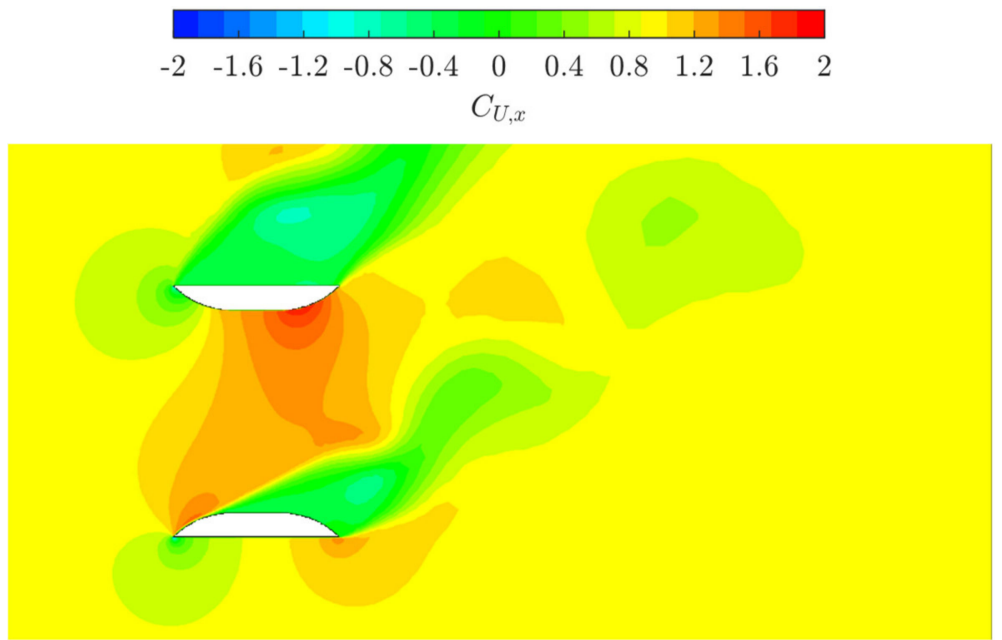

(c)

Figure 12. Illustrative cross-sectional representation of the axial velocity coefficient $\left(C_{U, x}\right)$ within the duct domain at distinct yaw angles $\left(U_{\infty}=4 \mathrm{~m} . \mathrm{s}^{-1}\right)$. (a) $\gamma=0^{\circ} ;(\mathbf{b}) \gamma=23.2^{\circ}$; (c) $\gamma=38^{\circ}$. 

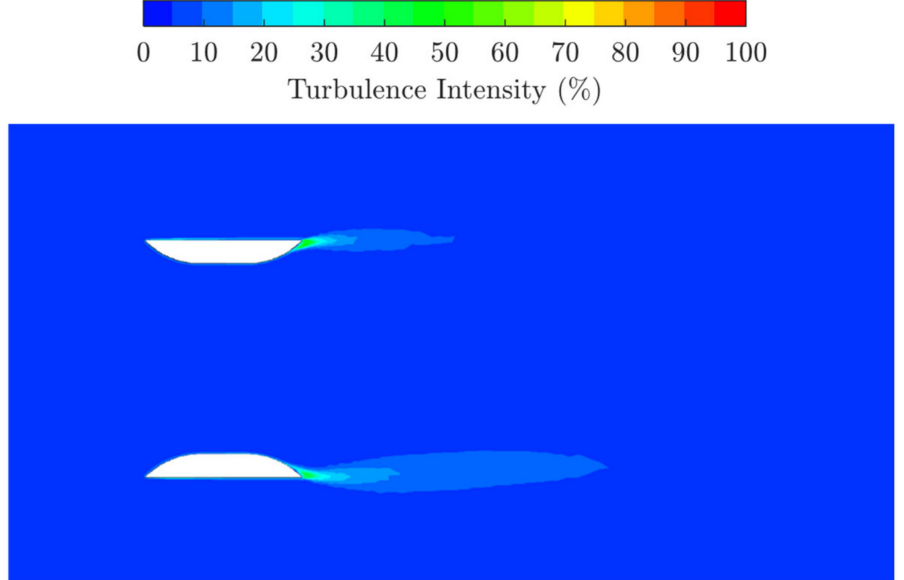

(a)
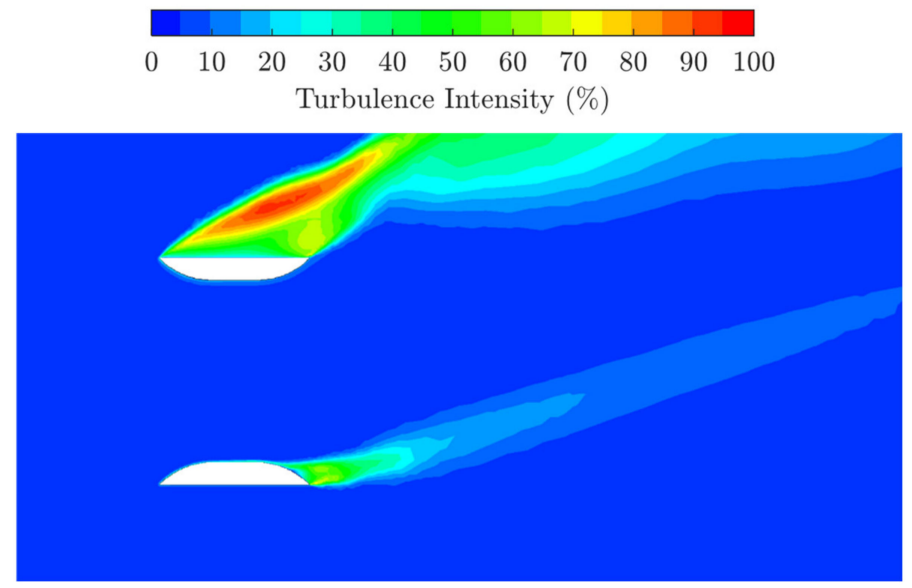

(b)
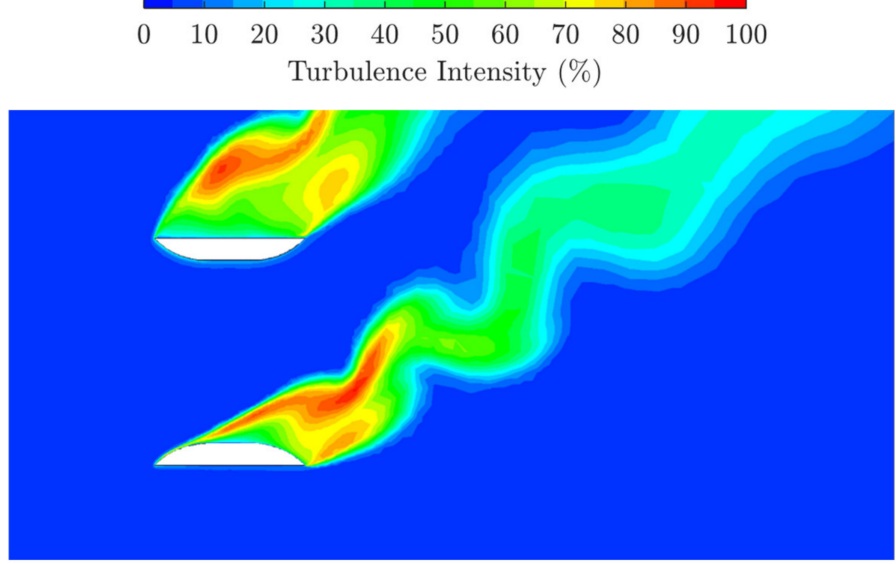

(c)

Figure 13. Illustrative cross-sectional representation of the turbulence intensity within the duct domain at distinct yaw angles $\left(U_{\infty}=4 \mathrm{~m} . \mathrm{s}^{-1}\right)$. (a) $\gamma=0^{\circ}$; (b) $\gamma=23.2^{\circ}$; (c) $\gamma=38^{\circ}$.

\subsection{Duct Pressure Coefficients}

To establish the angular flow-stream effects upon the wall static pressure induced along the duct surfaces, the distribution along the duct cross-section was analysed as depicted in Figure 14. The surfaces were discretised by their internal and external positions, in starboard and port directions. Furthermore, the static pressure within the domain cross-section is illustrated in Figure 15. 


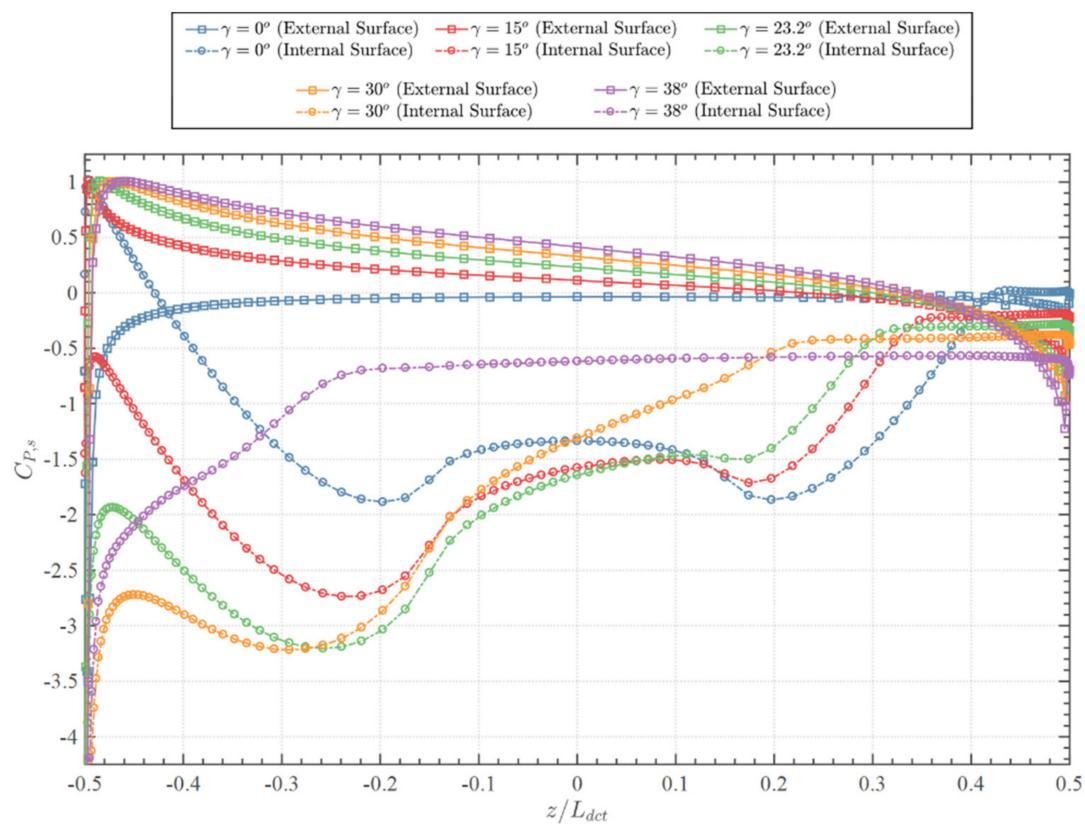

(a)

$\begin{array}{lll}-\square-\gamma=0^{\circ} \text { (External Surface) } & -\square-\gamma=15^{\circ} \text { (External Surface) } & -\square-\gamma=23.2^{\circ} \text { (External Surface) } \\ -\bullet--\gamma=0^{\circ} \text { (Internal Surface) } & -\bullet-\cdot-\gamma=15^{\circ} \text { (Internal Surface) } & -\bullet--\gamma=23.2^{\circ} \text { (Internal Surface) }\end{array}$

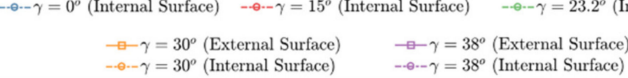

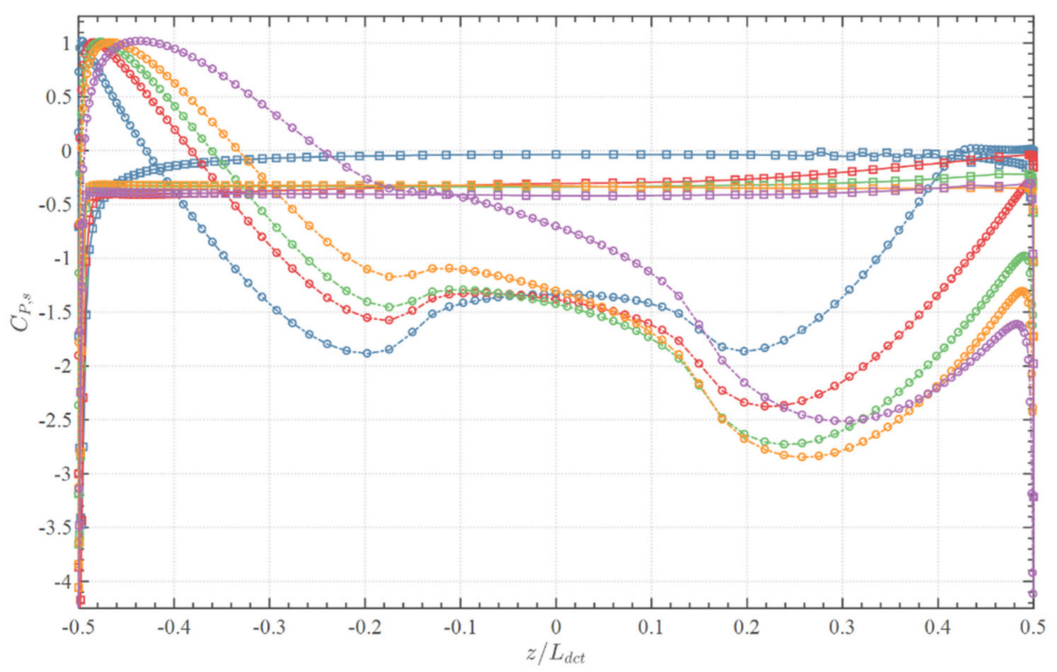

(b)

Figure 14. Evaluations of static pressure coefficient $\left(C_{P, s}\right)$ distribution along the duct surfaces at $\gamma=0^{\circ}$, $15^{\circ}, 23.2^{\circ}, 30^{\circ}, 38^{\circ}$. (a) Static pressure coefficient along the duct surfaces at port-side; (b) Static pressure coefficient along the duct surfaces at starboard-side.

At port, the stagnation point was located along the external surface, towards the leading edge, which shifted further downstream with an increase in yaw angle. This resulted in most of the external surface within the cross-section to be pressurised. The pressure at its trailing edge diminished with yaw bearing. Along the internal upstream curved surface, the pressure reduced in proportion to yaw angle up to a bearing of $30^{\circ}$. At the throat, the lowest wall pressure was attained at a bearing of $23.2^{\circ}$. Along the internal downstream curved surface, the pressure increased in proportion to the yaw angle. The effect of the laminar bubble and flow separation upon the static pressure at the throat was identified as the pressure increased marginally from $23.2^{\circ}$ to $30^{\circ}$, yet significantly from $30^{\circ}$ to $38^{\circ}$. 


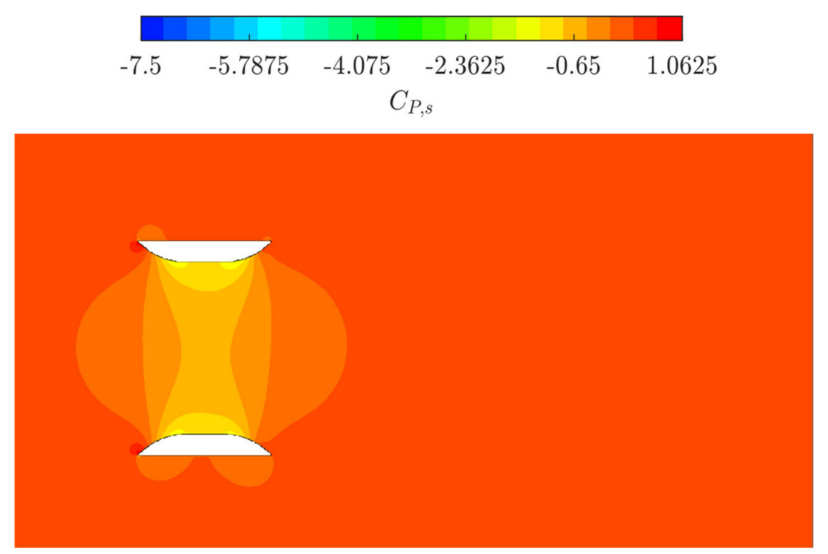

(a)
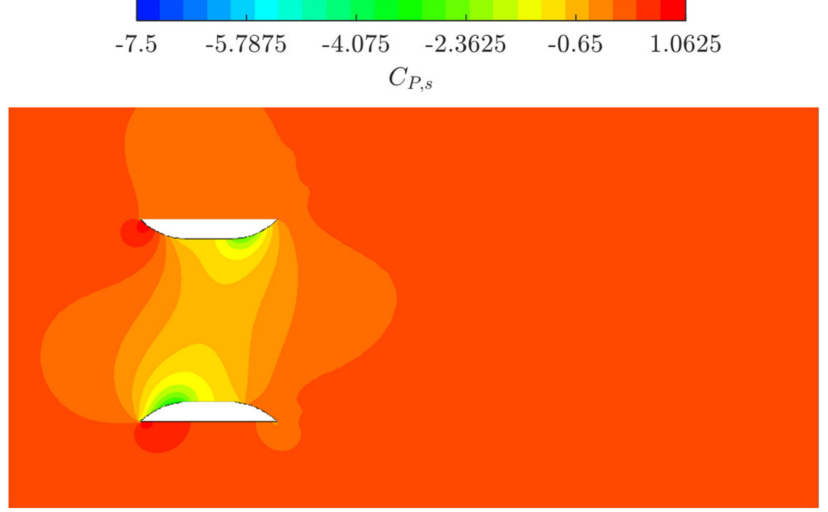

(b)
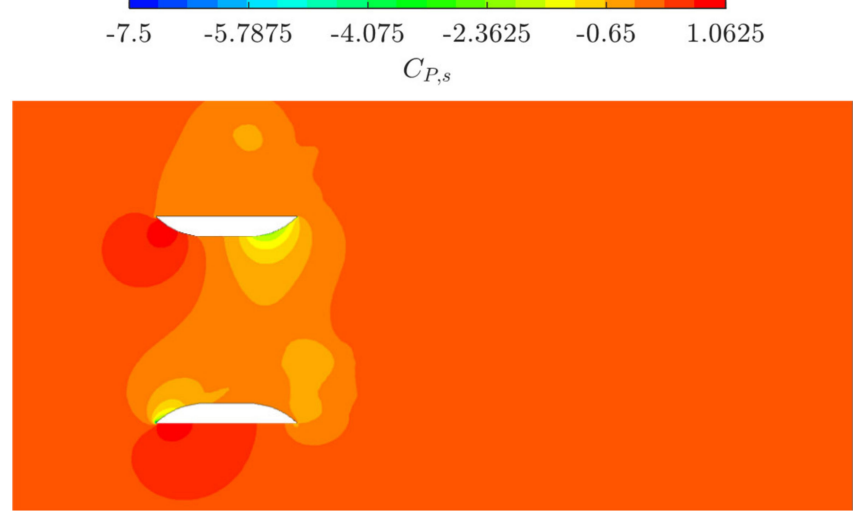

(c)

Figure 15. Illustrative cross-sectional representation of the pressure coefficient $\left(C_{P, s}\right)$ within the duct domain at distinct yaw angles $\left(U_{\infty}=4 \mathrm{~m} . \mathrm{s}^{-1}\right)$. (a) $\gamma=0^{\circ}$; (b) $\gamma=23.2^{\circ}$; (c) $\gamma=38^{\circ}$.

At starboard, quasi-identical outcomes were established. The stagnation point, however, occurred upon the internal surface. In addition, the variation in pressure at the curved starboard surfaces were inverted to that shown at port. Along the internal upstream curved surface, the pressure increased in proportion to yaw angle. The lowest wall pressure at the throat was also attained at a bearing of $23.2^{\circ}$. Along the internal downstream curved surface, the pressure decreased in proportion to the yaw angle.

\section{Discussion}

The swallowing capacity of a vacant bi-directional duct utilised for the purpose of ducted tidal turbine systems was numerically analysed by implementing computational fluid dynamic modelling. The analysis was undertaken to establish the potential augmen- 
tations in a rotor streamtube induced by the duct installation in both aligned and yawed flow conditions.

Within aligned flow conditions, the normalised axial velocity through the duct was acknowledged to increase beyond the free-stream as a result of the Bernoulli effect. The velocity increased further, proportional to the Reynolds number, due to a diminishment in pressure drag. The mass conservation equation was utilised to establish the width of the streamtube at the far-field position, which was found to increase with Reynolds number. Therefore, a higher mass-flow from an upstream position passed through the duct throat.

Within yawed flow conditions, the normalised axial velocity was further augmented by a maximum of $4.13 \%$ at a $23.2^{\circ}$ bearing. This increase in axial velocity came about due to the diminishment in static pressure within the duct throat, as the angle-of-attack between the duct section and the free-stream vector increased, permitting a higher flow-rate. The normalised axial velocity then decreased at yaw angles beyond the $23.2^{\circ}$ bearing due to the initiation of a laminar separation bubble, which increased static pressure within the throat. Flow separation was induced within the shroud beyond a flow bearing of $30^{\circ}$. As a result, pressure drag increased, leading to a significant reduction in the normalised axial velocity through the duct. With the reduced velocity, insufficient boundary layer momentum was present for the flow to re-attach at the downstream internal section of the duct, instituting diffuser stall.

\section{Conclusions}

The study analysed the hydrodynamic swallowing-capacity of a true-scale, vacant, cylindrical, bi-directional duct for tidal turbine applications in aligned and yawed inlet flows by utilising three-dimensional unsteady computational fluid dynamics. The performance was investigated within free-stream magnitudes of 1 to $7 \mathrm{~m} . \mathrm{s}^{-1}$, and a bearing angular range of $0^{\circ}$ to $45^{\circ}$ with the duct axis. This analysis was imperative to acknowledge the potential axial velocity increase through a rotor for augmented power generation.

The swallowing capacity was found to increase due to the reduction in pressure drag upon the duct with an increase in Reynolds number. Within yawed flow conditions, the augmentation occurred due to the duct-profile lift variation with angle-of-attack. At a nominal yaw angle of $23.2^{\circ}$, the static pressure at the throat was at its minimum, permitting the maximum mass-flow rate. Beyond the nominal angle-of-attack, the initiation of a laminar separation bubble, and subsequent flow separation, occurred within the duct. The flow features increased the static pressure within the throat, thereby reducing the swallowing capacity. The swallowing capacity of the duct was therefore acknowledged to be dependent on the Reynolds number and its nominal angle-of-attack to the free-stream yaw bearing.

Author Contributions: M.G.B.: conceptualization, methodology, software, validation, formal analysis, investigation, writing-original draft. Q.X.: writing—review and editing, supervision, resources, project administration. S.A.: conceptualization, writing-review and editing, resources, formal analysis, investigation. A.I.: funding acquisition, resources. C.P.: resources, supervision. All authors have read and agreed to the published version of the manuscript.

Funding: This research was funded by the EPSRC Supergen ORE Hub Flexible Fund Program Grant (Grant No. EP/S000747/1).

Acknowledgments: The research work disclosed in this publication is partially funded by the Endeavour Scholarship Scheme (Malta). Scholarships are part-financed by the European UnionEuropean Social Fund (ESF)—Operational Programme II-Cohesion Policy 2014-2020: "Investing in human capital to create more opportunities and promote the well-being of society", CCI number: 2014MT05SFOP001. Results were obtained using ARCHIE-WeSt High Performance Computer ( www.archie-west.ac.uk).

Conflicts of Interest: The authors declare no conflict of interest. The funders had no role in the design of the study; in the collection, analyses, or interpretation of data; in the writing of the manuscript; or in the decision to publish the results. 


\section{Appendix A}

In addition to the mean values of the analyses conducted within this study, the standard deviations of the results are illustrated in Figure A1. In comparison to the mean values, the deviations were acknowledged to be relatively minute.

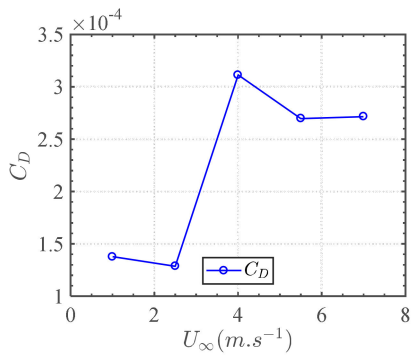

(a)

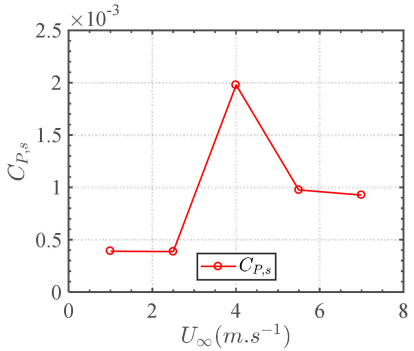

(c)

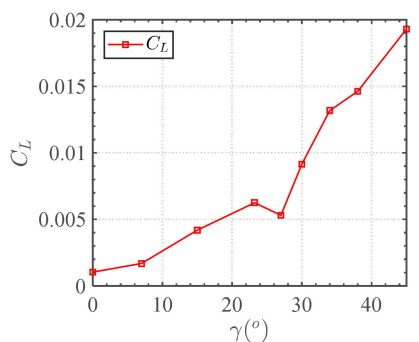

(e)

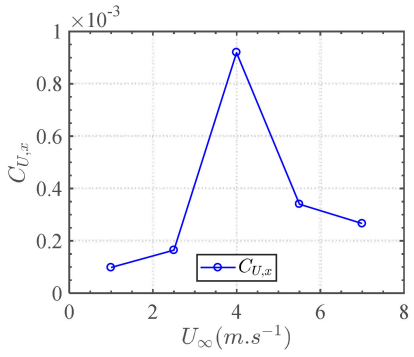

(b)

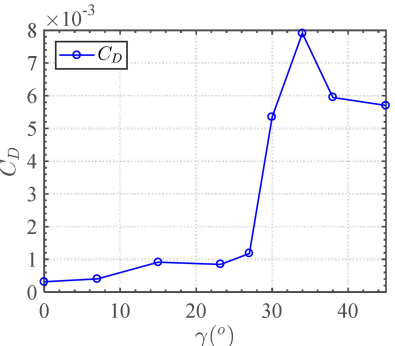

(d)

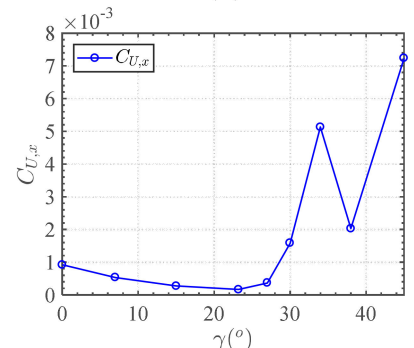

(f)

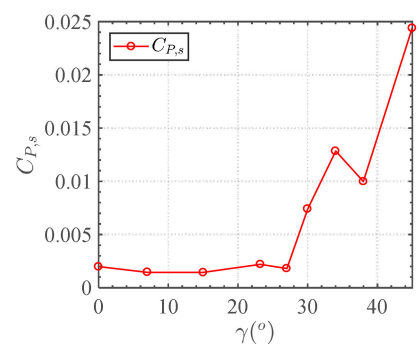

(g)

Figure A1. Evaluations of the standard deviation of the analyses conducted at aligned and yawed flows. (a) Evaluation of the duct drag coefficient $\left(C_{D}\right)$ with free-stream velocity $\left(U_{\infty}\right)$ within aligned flow conditions; (b) Evaluation of the duct axial velocity coefficient $\left(C_{U, x}\right)$ with free-stream velocity $\left(U_{\infty}\right)$ within aligned flow conditions; (c) Evaluation of the duct static pressure coefficient $\left(C_{P, s}\right)$ with free-stream velocity $\left(U_{\infty}\right)$ within aligned flow conditions; $(\mathbf{d})$ Evaluation of the duct drag coefficient $\left(C_{D}\right)$ with angular bearing $(\gamma)$ within yawed flow conditions; (e) Evaluation of the duct lift coefficient $\left(C_{L}\right)$ with angular bearing $(\gamma)$ within yawed flow conditions; (f) Evaluation of the duct axial velocity coefficient $\left(C_{U, x}\right)$ with angular bearing $(\gamma)$ within yawed flow conditions; $(g)$ Evaluation of the duct static pressure coefficient $\left(C_{P, s}\right)$ with angular bearing $(\gamma)$ within yawed flow conditions. 


\section{References}

1. European Commission (Luxembourg: Office for Official Publications of the European Communities). A European Green Deal. Available online: https:/ / ec.europa.eu/info/strategy/priorities-2019-2024/european-green-deal_en (accessed on 21 December 2020).

2. Rourke, F.O.; Boyle, F.; Reynolds, A. Tidal energy update 2009. Appl. Energy 2010, 87, 398-409. [CrossRef]

3. European Marine Energy Centre (EMEC) Ltd. Tidal Clients. Available online: http://tidalenergy.net.au/index-subpage-2.html (accessed on 2 February 2014).

4. Goundar, J.N.; Ahmed, M.R. Design of a horizontal axis tidal current turbine. Appl. Energy 2013, 111, 161-174. [CrossRef]

5. Kogan, F.A.; Seginer, A.T.A.E. Rep. No. 32A: Final Report on Shroud Design: Tech. Rep.; Department of Aeronautical Engineering, Technion-Israel Institute of Technology: Haifa, Israel, 1963.

6. Bloomberg, L.P. OpenHydro Group Ltd. Available online: https://www.bloomberg.com/profile/company /4074464Z:ID2018 (accessed on 24 December 2020).

7. OpenHydro Group Ltd. Projects. Available online: http://www.openhydro.com/Projects (accessed on 13 August 2017).

8. The Canadian Press. Cape Sharp Tidal Turbine in Bay of Fundy Now Being Monitored Remotely. Available online: https: / / www.cbc.ca/news/canada/nova-scotia/cape-sharp-tidal-turbine-remote-monitoring-environment-1.4814069 (accessed on 15 September 2018).

9. Ohya, Y.; Karasudani, T.; Sakurai, A.; Abe, K.; Inoue, M. Development of a shrouded wind turbine with a flanged diffuser. J. Wind Eng. Ind. Aerodyn. 2008, 96, 524-539. [CrossRef]

10. Masukume, P.; Makaka, G.; Tinarwo, D. Optimum Geometrical Shape Parameters for Conical Diffusers in Ducted Wind Turbines. Int. J. Energy Power Eng. 2016, 5, 177-181.

11. Masukume, P.-M.; Makaka, G.; Mukumba, P. Optimization of the Power Output of a Bare Wind Turbine by the Use of a Plain Conical Diffuser. Sustainability 2018, 10, 2647. [CrossRef]

12. Setoguchi, T.; Shiomi, N.; Kaneko, K. Development of two-way diffuser for fluid energy conversion system. Renew. Energy 2004, 29, 1757-1771. [CrossRef]

13. Cresswell, N.W.; Ingram, G.; Dominy, R. The impact of diffuser augmentation on a tidal stream turbine. Ocean Eng. 2015, 108, 155-163. [CrossRef]

14. Kardous, D.M.; Chaker, R.; Aloui, F.; Nasrallah, S.B. On the dependence of an empty flanged diffuser performance on flange height: Numerical simulations and PIV visualizations. Renew. Energy 2013, 56, 123-128. [CrossRef]

15. Kannan, T.S.; Mutasher, S.A.; Lau, Y.K. Design and flow velocity simulation of diffuser augmented wind turbine using CFD. J. Eng. Sci. Technol. 2013, 8, 372-384.

16. Mansour, K.; Meskinkhoda, P. Computational analysis of flow fields around flanged diffusers. J. Wind Eng. Ind. Aerodyn. 2014, 124, 109-120. [CrossRef]

17. Khamlaj, T.A.; Rumpfkeil, M.P. Analysis and optimization of ducted wind turbines. Energy 2018, 162, 1234-1252. [CrossRef]

18. Kesby, J.E.; Bradney, D.R.; Clausen, P.D. Determining diffuser augmented wind turbine performance using a combined CFD/BEM method. J. Phys. Conf. Ser. 2016, 753, 10736-10774. [CrossRef]

19. El-Zahaby, A.M.; Kabeel, A.; Elsayed, S.; Obiaa, M. CFD analysis of flow fields for shrouded wind turbine's diffuser model with different flange angles. Alex. Eng. J. 2017, 56, 171-179. [CrossRef]

20. Tampier, G.; Troncoso, C.; Zilic, F. Numerical analysis of a diffuser-augmented hydrokinetic turbine. Ocean Eng. 2017, 145, 138-147. [CrossRef]

21. Borg, M.G.; Xiao, Q.; Allsop, S.; Incecik, A.; Peyrard, C. A numerical performance analysis of a ducted, high-solidity tidal turbine. Renew. Energy 2020, 159, 663-682. [CrossRef]

22. Wilcox, D.C. Turbulence Modeling for CFD, 3rd ed.; DCW Industries, Inc.: San Diego, CA, USA, 2006.

23. Neill, S.P.; Jordan, J.R.; Couch, S.J. Impact of tidal energy converter (TEC) arrays on the dynamics of headland sand banks. Renew. Energy 2012, 37, 387-397. [CrossRef]

24. Bahaj, A.; Myers, L. Analytical estimates of the energy yield potential from the Alderney Race (Channel Islands) using marine current energy converters. Renew. Energy 2004, 29, 1931-1945. [CrossRef]

25. Pham, C.T.; Martin, V.A. Tidal current turbine demonstration farm in Paimpol-Brehat (Brittany): Tidal characterisation and energy yield evaluation with TELEMAC. In Proceedings of the 8th European Wave and Tidal Energy Conference, Uppsala, Sweden, 7-8 September 2009.

26. Pham, C.; Pinte, K. Paimpol-Bréhat tidal turbine demonstration farm (brittany): Optimisation of the layout, wake effects and energy yield evaluation using TELEMAC. In Proceedings of the 3rd International Conference on Ocean Energy, Bilbao, Spain, 6-7 October 2010.

27. Mason-Jones, A.; O’Doherty, D.M.; Morris, C.E.; O’Doherty, T.; Byrne, C.B.; Prickett, P.W.; Grosvenor, R.I.; Owen, I.; Tedds, S.; Poole, R.J. Non-Dimensional Scaling of Tidal Stream Turbines. Energy 2012, 44, 820-829. [CrossRef]

28. Resistance Committee of the 28th ITTC. Uncertainty Analysis in CFD Verification and Validation, Methodology and Procedures; Technical Report; ITTC: Zürich, Switzerland, 2017.

29. Mycek, P.; Gaurier, B.; Germain, G.; Pinon, G.; Rivoalen, E. Experimental study of the turbulence intensity effects on marine current turbines behaviour. Part I: One single turbine. Renew. Energy 2014, 66, 729-746. [CrossRef] 